\title{
Telemedicine: a Bridge Over Knowledge Gaps in Healthcare
}

\author{
Evelyn Eisenstein $^{1,2} \cdot$ Cristiane Kopacek $^{2,3} \cdot$ Suzy Santana Cavalcante ${ }^{2,4,5} \cdot$ Almir C. Neves $^{2,6} \cdot$ Gustavo P. Fraga ${ }^{2,7}$. \\ Luiz Ary Messina ${ }^{2}$
}

Published online: 1 July 2020

(C) Springer Science+Business Media, LLC, part of Springer Nature 2020

\begin{abstract}
Purpose of the Review The purpose of the review is to describe the Brazilian Telemedicine University Network RUTE concerning the Special Interest Group of Children and Adolescents, the new SIG-COVID19-BR activities for continuing medical education, and to update relevant information regarding diagnosis and treatment, using digital technologies.

Recent Findings A total of 145 sessions of video and webconferences were held with the participation of 6575 health professionals, including medical students, interns, and residents. Major topics involved the healthcare of children and adolescents were combined with the emergence of a new pandemic plus the need to decrease the professional knowledge gaps in geographically distant hospitals.

Summary Telemedicine is a cost-effective tool and a bridge to decrease health disparities access for proper care and assistance for any population. RUTE is a Brazilian model of telemedicine which has a positive impact attracting the participation of health professionals, and even more so, during the Covid-19 virus pandemic outbreak.
\end{abstract}

Keywords Telemedicine $\cdot$ Pediatric healthcare $\cdot$ Distance learning $\cdot$ Medical training $\cdot$ Videocollaboration $\cdot$ Webconferences

\section{Introduction}

The discovery of new space possibilities, to reach out for new horizons and to fight against diseases has been medical and scientific challenges for many centuries. Recently, there has been an increased leverage via the use of rapid image and voice technologies, including the internet and digital communication.

This article is part of the Topical Collection on Adolescent Medicine

Evelyn Eisenstein

evelynbrasil@hotmail.com

1 University of the State of Rio de Janeiro (UERJ), Rio de Janeiro, Brazil

2 RUTE, Brazilian University Telemedicine Network, Rio de Janeiro, Brazil

3 Federal University of Health Sciences of Porto Alegre (UFCSPA), Porto Alegre, Brazil

4 Department of Pediatrics, Federal University of Bahia (UFBA), Salvador, Brazil

5 TeleHealth (NUTS), Salvador, Brazil

6 Department of Women, Child and Adolescent Health, Federal University of Ceará (UFC), Fortaleza, Brazil

7 School of Medical Sciences, University of Campinas (UNICAMP), Campinas, Brazil
Telemedicine is one of these innovative tools to help connect health professionals, different medical practices, and specializations, including pediatric healthcare all over the world. Beginning in 2006, Brazil began to address the obstacles, with the development of the Brazilian University Telemedicine Network (Rede Universitaria de Telemedicina, RUTE) linking federal and state university hospitals and medical schools [1•]. The Special Interest Group (SIG) of Children and Adolescent Medicine and Health was the second SIG created during 2008 with partnership and collaboration between pediatricians from the Federal University of Bahia (UFBA) and the State University of Rio de Janeiro (UERJ). This major decision was one of the foundations of a new telemedicine bridge that has been constructed and empowers as many as 61,033 health professionals, including residents and medical students, since then. RUTE is a collaborative network nationwide which started to register participation directly online, after 2015. The organization, planning, and implementation of 6508 video and webconferences have been shared between Brazilian universities and international guest speakers, with two to three daily activities that also occur with 55 other SIGs of different areas of interest [ $1 \bullet]$.

In the beginning of 2020, the challenges raised by the Covid-19 pandemic were another reason for the development and structure of a new SIG called COVID-19-BR. Since March 23, 2020, there have been 23 national and international webconferences and state- 
of-the-art professional exchanges on diagnosis, care, and treatment options, including networking with medical professionals from Israel, Italy, Portugal, Spain, Switzerland, and USA. RUTE has also pioneered professional and health liaisons with many Latin American/RedCLARA and Portuguese speaking countries, as part of CPLP/Comunidade de Países da Lingua Portuguesal Community of Portuguese Language Countries [2, 3]. More byside telemedicine bridges and network opportunities have been constructed along with other medical and health professions members of Healthcare Information for All in Portuguese/HIFA-pt and Children's Healthcare Information for All/CHIFA [4].

\section{Definition and Background}

Telemedicine has been defined as the use of telecommunication and information technologies to support the delivery of healthcare at a distance. Telehealth has a broader definition, encompassing telemedicine's clinical care and tele-education for research, disaster planning, and primary healthcare at geographically distant and poorer areas. Telemedicine and telehealth are commonly used today and are considered synonymous or complementary to each other $[5,6 \bullet]$. The World Health Assembly WHA71.7, Agenda item 12.4 on May 26, 2018, recalling resolutions WHA58.28 (2005) on eHealth, and WHA66.24 (2013) on eHealth standardization and interoperability, emphasized the benefits, opportunities, and challenges for countries, considering an even broader area as digital health [7•].

Telemedicine involves, not only sharing of information between experts, but also distance education and efficient collaboration with decision-making in real-time, including videocollaborations, audiovisual tools, and exchange of documents and up-to-date protocols. It enables people who cannot be physically present to start a respectful conversation or discussion of difficult clinical case or themes to overcome obstacles in diagnostic or treatment procedures. It also allows the sharing of files and data so that it is easier and faster to reach out or review documents to make universal health coverage achievable. Concerns about ethics, data confidentiality, informed consent, confidence, and medical security are always essential components of this bridge construction, ensuring transparency is a part of this technological digital strategy option $[7 \bullet, 8]$.

Brazil has an estimated population of 204 million people, of which $34 \%$ are children and adolescents corresponding to 65 million individuals between 0 to 19 years of age, with social, educational, and health disparities and inequalities. Even so, all are considered subjects with their own rights with social protection assured by the Family and the State, with absolute priority by the Federal Constitution (1988) article no. 227, based with the United Nations Convention of the Rights of the Child (UN-CRC) [9]. There is a free public health system throughout the country with medical assistance and health services available in each municipality, Sistema
Unico de Saúde (SUS) under the responsibility of the Ministry of Health [10].

Due to its large land mass of $8514.877 \mathrm{~km}^{2}$, Brazil is divided into 5 major regions and 27 states. Eighty-three percent of people live within urban areas and some $17 \%$, which corresponds to 33 million people, live in rural, including indigenous remote areas, mainly in the North, Northeast, and Central regions (Amazonas, Pará, Amapá, Acre, Roraima, Rondonia, Mato Grosso, Maranhão, Piaui). The education of health professionals across such large and diverse areas is a difficult task. That said, Portuguese is the common language, and the internet is crucial, for communication and information throughout the country.

Brazil has established a safe and innovative space for the discussion of strategic issues related to the development of the internet and its governance in the country. Throughout its development, the Brazilian Internet Steering Committee (CGI.br) played an important role for the global debate on internet governance with the goals to support the formulation, implementation, and evaluation of public policies to foster the use of Information and Communication Technologies (ICT). Its main goal is to improve the internet and to contribute to digital inclusion, with more open and transparent debates and planning of public policies. The major federal and state public universities are connected through the Telemedicine University Network RUTE [1•] with the Ministry of Science and Technology and National Research and Education Network NREN (Rede Nacional de Ensino e Pesquisa RNP) support. RNP connects all public and private research and education ( $R \& E$ ) institutions nationally, but regarding health R\&E institutions, its main objective is to connect the several university and teaching hospitals in the country into a single information network under the umbrella of RUTE.

Currently, there are 139 Brazilian universities connected within the RUTE network with 27 (20\%) located at distant points in the country. One example is the Amazon north region is the teleassistance for the so-called basic health unit in 62 municipalities that are connected with the specialists from the Federal University of Amazonas (UFAM) for second opinions using RUTE technology. There are 55 different groups of specialization called SIGs, dedicated to specific health areas, e.g., cardiology, dermatology, human milk bank, indigenous health, medical education, data science and artificial intelligence (AI), children and adolescent health, and pediatric endocrinology among many others. Once certified, participating institutions are free to propose, create, and coordinate special interest groups (SIGs) among their professional expertise, covering medical and health topics, all operating under RUTE's infrastructure and technical support (see Fig. 1).

Telemedicine has been relevant for the continuing education of medical and health multiprofessional residents. RUTE ran in 2015,2016 , and 2017, a nationwide update course for residency preceptors which involved hospitals in all 27 Brazilian states. There were on average 45 videoconference 


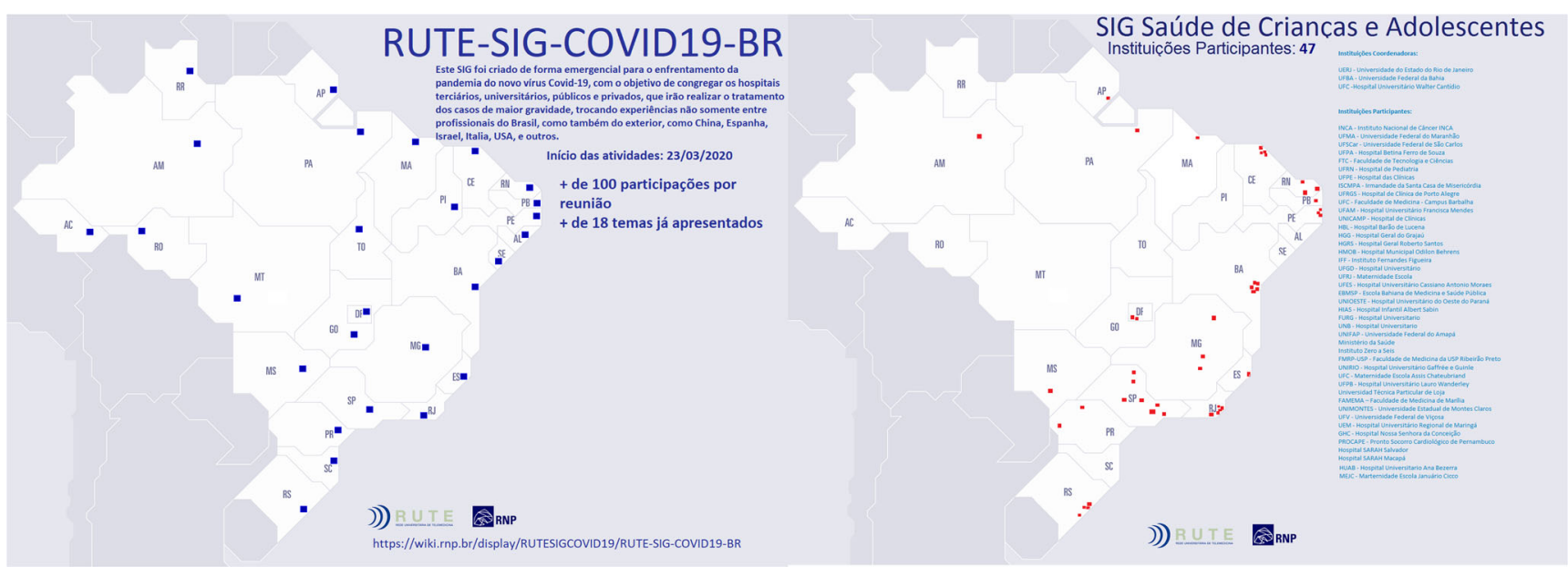

Fig. 1 Maps of the Brazilian universities and medical institutions that are members of the SIG for Children and Adolescent Health and Medicine and the SIG COVID-19-BR of the Brazilian University Telemedicine Network, SIG-RUTE-BRAZIL-2020

rooms and 617 health professionals every week during 12 weeks and 2-h session/week, having more than 7000 participants and a cost avoidance of circa 4 Million US\$ [1•].

Telemedicine can be a useful tool for the training of teams and, for this main reason, it is becoming more frequently used in several areas of capacity building and medical trainings. It was adopted for the preparation of hospitals for disasters and catastrophes before the FIFA World Cup, in 2014, and the Summer Olympics, in 2016 [11]. A study showed a disaster preparedness course via telemedicine was one of the solutions to overcome the logistical and cost obstacles involved in the rapid and decentralized training of teams with gain in knowledge by participants in a distance-learning course [11].

\section{Pediatric Healthcare}

Since 2008, there have been 122 videoconferences implemented by the 47 medical institutions and teaching hospitals with pediatric services which integrate the SIG for Children and Adolescent Medicine and Health. At the present time, we also have the support of the Brazilian Pediatric Society/Sociedade Brasileira de Pediatria with some telemedicine sessions and other special debates which have resulted in scientific documents then disseminated through the society's website [12].

Videoconferencing occurs once or twice a month, for $1 \mathrm{~h}$ with half hour for a question and answer period. It is always very interactive with lively discussion, including residents, interns, and medical students in addition to the staff or the guest speaker and the moderator. It is structured with a very holistic and humanistic approach covering the interdisciplinary aspects of the theme or the clinical case presented and discussed also by the team's psychologist, social services, or invited physiotherapists, accordingly. There is a rotation between the institutions depending on the demands or updates. All videoconferences are saved on the RUTE public digital video library and databank and are freely available for consultation, thereafter [1].

During the past 12 years, discussion of complex medical cases with consultation to obtain second opinions was completed through international videoconferences, which had a positive impact. A few of our (SIG-RUTE) collaborators are from Center on Media and Child Health/CMCH at Children's Hospital in Boston, MA; Medical Missions for Children/ MMC at Children's Hospital in Patterson, NJ; The Johns Hopkins Hospital and Medical Institutions in Baltimore, MD; Georgetown University Hospital in Washington, DC; and Children's Hospital in Sydney, Australia. Videoconferences also have been held with the Pan American Health Organization in Washington, DC, and with the World Health Organization in Geneva [13].

Some public health education campaigns were launched, simultaneously through a telemedicine session with the Children's Hospital in Sydney, Australia, including the shaken baby syndrome, with the translated video saved at a YouTube platform and having more than 82,000 views, since 2009 [14]. This theme of abusive head trauma was afterward recognized as a priority for another initiative on violence prevention and a scientific literature review was published [15]. Another educational video on violence and abuse prevention with interventions was produced with support from the International Society for Prevention of Child Abuse and Neglect (ISPCAN). It became part of the content for an online course through the TeleHealth Service (UERJ). During the period of 5 years, more than 7000 health professionals completed the 10 modules with 60-min webconference sessions and evaluation of field cases presented by the participants after completion of a 10-h e-education practical course [16].

Major telemedicine sessions and topics of the video/ webconferences implemented which had greater impact in respect to participation can be categorized as follows: 
- Epidemic outbreaks: dengue fever, zika, chikungunya, yellow fever, measles, and other viral infections, like H1N1 and the recent coronavirus (Covid-19);

- Early diagnosis of developmental disorders: autism spectrum disorder, Asperger's syndrome, speech delay, cerebral palsy, and inborn errors of metabolism;

- Health rights and ethics: social violence, sexual abuse, adoption, drugs, and alcohol;

- Nutritional and eating disorders: anorexia, bulimia, overweight, obesity, and anemias;

- Endocrine disturbances affecting children and adolescents: congenital and acquired thyroid and adrenal diseases, disorders of sex development, diabetes, growth and puberty disorders, and endocrine tumors;

- Breast feeding health campaigns and protocols;

- Teenage pregnancy and sexually transmitted infections/ HIV, HPV, HepC;

- Immunizations and yearly vaccination calendar, public health campaigns;

- Traumatic care, accidents, burns, drowning, and preventive measures;

- Mental health and behavioral problems: school dropouts, suicide, attention deficit disorder and hyperactivity, and family therapy;

- Indigenous health and major respiratory outbreaks;

- Digital health: gaming, privacy and safety online, and hazardous games

\section{Covid-19}

During January 2020, a cluster of cases of pneumonia and respiratory diseases was reported in China, and on January 22, the World Health Organization (WHO) issued the first statement that there was evidence of a new coronavirus with human-to-human transmission [17]. International news sounded an alert on February 3, when WHO released a document with the strategic preparedness and response plan to help protect states with weaker health systems outlining the public health measures that the international community stands ready to provide support in case of such epidemic emergency, including the use of telemedicine [18•]. On March 11, due to the alarming levels of spread, severity, and high transmissibility with increase of death rate tolls, WHO declared the new virus outbreak as a pandemic. The first Brazilian death from Covid19 occurred in São Paulo, on March 17, 2020.

RUTE's national coordination team organized one extra national advisory scientific planning committee meeting in March 20, 2020. The SIG COVID-19-BR was launched that day, as an emergency initiative between the leadership of the University of Campinas (UNICAMP), State University of Rio de Janeiro (UERJ), and Federal University of Health Sciences of Porto Alegre (UFCSPA). The first videoconference was held on
March 23, with the participation of all RUTE's health professionals for collective planning of the several institutional demands, resource needs, and knowledge gaps for information on diagnosis and treatment of the new viral disease Covid-19.

The SIG COVID-19-BR professional network meets three times a week, during lunch break for $1 \mathrm{~h}$, for national and international webconferences to facilitate the transmission of video materials and all medical protocols with the possibility of a chat with questions and answers for the final debate period. All presentations are recorded with prior permission and saved for future public consultations at RUTE's special Wiki website [19•].

So far, there have been 23 presentations through webconferencing and streaming with invited guest speakers from Israel, Italy, Spain, Portugal, and USA sharing their expertises and difficulties on diagnostic tests and exams. There have been large debates with participation of medical professionals from 22 different Brazilian states out of 27, including an average of 100 participants for each session, while a shared session between SIG COVID-19-BR and SIG Pediatrics Endocrinology on May 11 registered 181 participants.

It is also important to highlight the participation of medical students, interns, and residents during the SIG COVID-19BR. Medical and nursing students, assisted by their professors, presented their orientation work as they are helping with prevention actions and informing the general public with the program called ORIENTA+Covid-19, created at UNICAMP. So far, they have attended to more than 1000 telephone calls from the population searching for Covid-19 safe recommendations. This model regarding students trained by professors to give recommendations to the population is also creating a new SIG to stimulate and disseminate the model to other universities in Brazil. Some already have such a similar procedure, enabling the start of a national health student network, professor oriented, and student focused on health prevention for the population, enhancing their professional education on primary healthcare.

Another special initiative was held with the partnership of RUTE and RNPI (Rede Nacional pela Primeira Infancia) National Network for Childhood, with a webconference on the mental health secondary repercussions within the families with children at home during the quarantine period. This was an open and public national session directed to parents, journalists, and educators from 12 different states and demonstrated that RUTE's professional network can also have a positive impact for the general public as a health education dissemination tool $[1 \bullet]$.

\section{Discussion}

Science is the search for the unknown and medical science is the search for diagnosis, treatment, and healthcare for any disease and other morbidities affecting anyone anywhere in the world. Telemedicine has been a virtual electronic bridge 
between medical specialists at the teaching hospital and the remote attending physicians, who can be geographically distant, but share their knowledge and practical expertises at the same time, talking and seeing each other on the other side of the computer screen, in a digital room. The challenges are not only immediate communication with efficient technical support, but also the outreach for a diagnosis and sharing any protocols to decrease the knowledge gap between medical colleagues as partners, even at distantly related community hospitals or basic health units, in different areas of the country. It is also an opportunity to establish a deeper connection toward human and health rights, to give and to receive the best possible answer for care, cure, or control of a specific disease, with the priority for children and adolescents, including the use of secure digital environment $\left[11,20^{\bullet}\right]$.

The importance of capacity building and professional or academic medical training and positive continuing medical education toward some more complex diagnosis has also played a secondary but integrated role for the video and webconferences. These sessions are recorded and broadcast or reviewed, anytime with open access by other physicians or medical students or they are used as a forum for global learning.

The professional network and experience developed during the past 12 years with the SIG Children and Adolescents Health and Medicine and other SIGs with the technical support of RUTE was a significant step to the rapid response to the Covid-19 challenge. Telemedicine provided the right tool for the initiative to enhance medical information breakthroughs to distant university hospitals in Brazil.

The emergence of the pandemic also raised some legal and regulatory aspects about rules and criteria for appropriate teleconsultation between health professionals who are hospitalbased or privately based. The Federal Council of Medicine had released a resolution CFM 1643/2002 defining telemedicine as the practice of medicine through the use of audiovisual interactive methodologies with communication of data for the objectives of medical assistance, education, and health research. Only recently, a new resolution has been approved for the exercise of telemedicine for all Brazilian states [21]. As Brazil is now considered to be in a state-of-emergency due to the Covid-19, a new telemedicine law has been approved recently by the Ministry of Health enabling the so-called teleconsultation direct between local physicians taking care of a hospitalized or ambulatory patient with a remote specialist through the digital screen, which had not been permitted before [22].

To practice medicine is a professional commitment to share knowledge with a team in any hospital and also to keep updated with scientific, practical content. Telemedicine offers a perfect tool for this exercise. The university and teaching hospitals are always a place for knowledge mentorship, renewal, and prestige, especially when allocating available time for networking with other professionals around the country or internationally.
It is also important to focus on the positive educational impact for medical students, interns, residents, staff, and multidisciplinary teams. These groups learn and share concerns during the lively and respectful interaction and question and answer period following the main presentation of the telemedicine topic chosen at that session.

\section{Conclusions}

Telemedicine represents an important tool for the education of medical professionals and the distance learning to provide medical diagnosis and treatment, direct and indirectly with outreach and screening programs, especially for children and adolescents in poorer areas in Brazil. It has been also a more effective collaborative research tool creating a digital space for interaction, teleassistance to the health professionals, and also teleconsultation direct to the patient, beside image diagnosis and second opinion.

To facilitate the transfer of medical knowledge from its source in research centers, by the use of audiovisual and digital equipment, is a way to decrease the information gaps for healthcare providers at underserved hospitals. It is more than a technological or communication challenge; it is a bridge constructed over troubled water [23].

The professional commitment of healthcare workers is an example of a vital task that can be eased by the use of telemedicine. This is a cost-effective method available for any hospital or even during any emergency, like a disaster, by overcoming personal or technological barriers.

The insertion of ICTs for the consolidation of digital health, telemedicine, and telehealth is inevitable, demonstrating the guarantee of the effective and efficient application of health services to the entire population, finally allowing governance based on scientific, reliable, safe, certified, and governed information under the general data protection law.

Much has been accomplished so far through telemedicine to implement healthcare for children and adolescents in Brazil. The Covid-19 pandemic has allowed some processes to accelerate, expanding telemedicine's sphere of action in both education and assistance. Brazilian universities, with the support of RUTE, have applied their range of performance, bringing a clear benefit to improving healthcare for the entire population. The way is open for many present and future initiatives, in which telemedicine will certainly be the differential, here and worldwide.

Acknowledgments Thiago Lima Verde, Luan Meirelles, Max Moraes (RUTE); Mario João Jr. (UERJ); Jeferson Batista dos Santos, Thiago Santana Dias, Samuel Lima de Farias, Bruno da Silva Santos (NUTS, $U F B A)$; Antonio Carlos da Silva (UNICAMP) for their technical support; Frank and Peggy Brady from Medical Missions for Children; Pierre Rodriguez from Poly; John P Howard for revision. 


\section{Compliance With Ethical Standards}

Conflict of Interest The authors declare no conflict of interest.

Human and Animal Rights and Informed Consent This article does not contain any studies with human or animal subjects performed by any of the authors.

\section{References}

Papers of particular interest, published recently, have been highlighted as:

- Of importance

1. RUTE, Rede Universitária de Telemedicina / Brazilian Telemedicine University Network. Available at: http://www.rute. rnp.br website with the description of all universities and activities of video and webconferences implemented by the SIGs of RUTE.

2. RedCLARA. Available at: http://www.redclara.net/index.php/en.

3. CPLP. Comunidade dos Paises da Lingua Portuguesa / Community of Portuguese Language Countries. Available at: http://www.cplp. org.

4. HIFA. Healthcare Information for All. Available at: http://www. hifa.org.

5. Pereira BM, Calderan TR, Silva MT, Silva AC, Marttos AC, Fraga GP. Initial experience at a university teaching hospital from using telemedicine to promote education through videoconferencing. Sao Paulo Med J. 2012;130(1):32-6.

6. Burke BL, Hall RW. Telemedicine: pediatric applications. Pediatrics. 2015;136(1):e293-308. https://doi.org/10.1542/peds. 2015-1517 Complete description of telemedicine and telehealth applied to pediatrics with criteria and characteristics for connection and basic items for consultation.

7. World Health Organization. Global Diffusion of eHealth making universal coverage achievable. Report of the third global survey on eHealth. 2016. Available at: https://apps.who.int/iris/bitstream/ handle $/ 10665 / 252529 / 9789241511780$-eng.pdf;jsessionid= B6894C1D7DA9D88508B6A08FBBC61458? sequence $=1$. International document with overview of how telemedicine and e-health concepts are broadly applied to make a better universal healthcare achievable, including for poorer countries.

8. Langarizadeh M, Moghbeli F, Aliabadi A. Application of ethics for providing telemedicine services and information technology. Mediev Archaeol. 2017;71(5):351-5. https://doi.org/10.5455/ medarh.2017.71.351-355.

9. Brasil. Constituição Federal (1988). Estatuto da Criança e do Adolescente, ECA, Lei \#8069 (1990).

10. Castro MC, Massuda A, Almeida G, Menezes-Filho NA, Andrade MV, Noronha KVM, et al. Brazil's unified health system: the first 30 years and prospects for the future. Lancet. 2019;394(10195): 345-56. https://doi.org/10.1016/S0140-6736(19)31243-7.

11. Dorigatti AE, Pereira BMT, Simões RL, Matsuguma JR, Calderan TRA, Fraga GP. In-person and telemedicine course models for disaster preparedness: a comparative analysis. Rev Col Bras Circ. 2018;45(3):e1710. https://doi.org/10.1590/0100-6991e-20181710.

12. SBP. Sociedade Brasileira de Pediatria / Brazilian Pediatric Society. Available at: http://www.sbp.com.br.

13. Eisenstein E, Messina LA. Broadening the frontiers of adolescent health through telemedicine and online networks. Ann Glob Health. 2017;83(5-6):713-7. https://doi.org/10.1016/j.aogh.2017.10.028.

14. SBS. Sindrome do Bebê Sacudido / Shaken baby syndrome. Available at: https://www.youtube.com/watch?v= o0vASBX8CQ0\&t=32s.

15. Lopes NR, Eisenstein E, Williams LC. Trauma Craniano Violento Pediátrico: revisão deliteratura / Abusive Head Trauma in Children: a literature review. J Pediatr. 2013;89:426-33. https://doi.org/10. 1016/j.jpedp.2013.01.012.

16. TelesSaude UERJ. Report of the Telehealth course: prevention of violence and child abuse (2012-2017). Available at: http://www. telessaude.uerj.br/resource/goldbook/pdf/16.pdf/.

17. WHO. World Health Organization: Mission summary: WHO field visit to Wuhan, China, 20-21 January 2020. Available at: https:// www.who.int/china/news/detail/22-01-2020-field-visit-wuhanchina-jan-2020.

18. WHO. World Health Organization: srategic preparedness and response plan, 3 February 2020. Available at: https://www.who.int/ publications-detail/strategic-preparedness-and-response-plan-forthe-new-coronavirus. The first WHO document with the alert of the new Covid-19 pandemic with strategies responses for all countries.

19. RUTE. Rede Universitária de Telemedicina / Brazilian Telemedicine University Network: SIG-COVID-19 Wiki. Available at: https://wiki.rnp.br/display/RUTESIGCOVID19. RUTE's wiki site with vídeos and materials saved during the webpresentations made accessible and free for public consultations, study or reviews on Covid-19 pandemia.

20. United Nations Human Rights. Committee on the Rights of the Child, UN-CRC. Available at: https://www.ohchr.org/EN/ $\mathrm{H} \mathrm{R} \mathrm{B} \mathrm{o} \mathrm{d} \mathrm{i} \mathrm{e} \mathrm{s} \mathrm{/} \mathrm{C} \mathrm{R} \mathrm{C} \mathrm{/} \mathrm{P} \mathrm{a} \mathrm{g} \mathrm{e} \mathrm{s} \mathrm{/}$

GCChildrensRightsRelationDigitalEnvironment.aspx. This is the most important document with its 54 articles especially article \# 24 for the highest attainable standard of health and that no child should be deprived of the right to acess healthcare services, a unique international premise of the medical work, including the telemedicine efforts and support.

21. CFM. Conselho Federal de Medicina/ Federal Council of Medicine. N 1756/2020. COJURofficial letter of 03/19/2020 Available at: http://portal.cfm.org.br/images/PDF/2020_oficio_ telemedicina.pdf.

22. Brasil. Lei 13.989 de 15 de Abril de 2020 sobre o uso da Telemedicina durante a crise causada pelo Coronavirus (SARSCoV-2)/ Brazil Law 13,989: April, 15, 2020 deals with the use of telemedicine during the crisis caused by coronavirus (SARS-CoV2). Available at: http://www.in.gov.br/web/dou/-/lei-n-13.989-de15-de-abril-de-2020-252726328.

23. Simon and Garfunkel. song: A bridge over troubled water. 1970. Available at: https:/www.youtube.com/watch?v=4G-YQA_bsOU.

Publisher's Note Springer Nature remains neutral with regard to jurisdictional claims in published maps and institutional affiliations. 